\title{
Kajian Konstruksi Hijau Pada Aspek Efisiensi Dan Konservasi Energi Pada Perumahan Komplek Villa Citra Kota Banda Aceh
}

\author{
Fakhrurrazi $^{1}$ Buraida $^{2}$ Nurul Malahayati $^{3}$ \\ 1,2,3 Jurusan Teknik Sipil, Universitas Syiah Kuala, Banda Aceh 2311, Indonesia \\ Email: ${ }^{1}$ Fakhrurraziii1995@gmail.com
}

\begin{abstract}
Abstrack
The energy crisis has become an increasingly important issue along with the progress of the times. Entering the 20th century, the need for energy is increasing in various fields, almost none of which does not require energy in carrying out activities. One effort that can be done in minimizing energy is by applying Green Building or green buildings. The most popular reference concept for implementing Green Building in Indonesia was issued by the Green Building Council Indonesia (GBCI), namely Greenship Homes Version 1.0. This study assessed the perceptions and application of energy efficiency and conservation aspects in accordance with the Greenship Homes Version 1.0 through research instruments in the form of questionnaires and direct interviews with respondents. The results showed that respondents' perceptions of Electricity Energy Savings were categorized as important to be applied with an average percentage value of 63.61\%, while for Greenship as a whole it could be categorized as good to be applied with an average percentage value of $55 \%$.
\end{abstract}

Keywords: Energy Efficiency and Conservation, Greenship Homes Version 1.0, Housing

\begin{abstract}
Abstrak
Krisis energi telah menjadi isu yang semakin penting seiring dengan kemajuan zaman. Memasuki abad ke-20, kebutuhan akan energi semakin besar dalam berbagai bidang, hampir tidak satupun bidang yang tidak membutuhkan energi dalam menjalankan kegiatan. Salah satu upaya yang dapat dilakukan dalam meminimalisir energi adalah dengan penerapan Green Building atau bangunan hijau. Konsep acuan paling populer untuk penerapan Green Building di Indonesia dikeluarkan oleh Green Building Council Indonesia (GBCI), yaitu Greenship Homes Version 1.0. Penelitian ini menilai persepsi dan penerapan aspek efisiensi dan konservasi energi sesuai acuan Greenship Homes Version 1.0 melalui instrumen penelitian berupa kuesioner dan wawancara langsung dengan responden. Hasil penelitian didapat bahwa persepsi responden terhadap Penghematan Energi Listrik dikategorikan penting untuk diterapkan dengan nilai persentase rata-rata $63,61 \%$, sedangkan untuk Greenship secara keseluruhan dapat dikategorikan baik untuk diterapkan dengan nilai persentase rata-rata $55 \%$.
\end{abstract}

Kata kunci: Efisiensi Dan Konservasi Energi, Greenship Homes Version 1.0, Perumahan

\section{Pendahuluan}

Rumah merupakan bangunan yang berfungsi sebagai tempat tinggal atau hunian dengan sarana dan prasarana lingkungan. Konsep rumah ramah lingkungan sudah sepatutnya memenuhi dasar layak huni dengan memenuhi persyaratan keselamatan bangunan dan kecukupan minimum luas bangunan serta kesehatan penghuninya. Rumah ramah lingkungan merupakan rumah yang bijak dalam menggunakan lahan, efisien, dan efektif dalam menggunakan energi maupun dalam menggunakan air, memperhatikan konservasi material sumber daya alam serta sehat dan aman bagi penghuni rumah. Perawatan rumah yang ramah lingkungan dan aman juga sangat penting yang harus disertai dengan perilaku ramah lingkungan oleh penghuninya.

Pemahaman konsep akan rumah ramah lingkungan merupakan faktor utama yang harus diprioritaskan untuk menghindari kesalahpahaman akan anggapan bahwa rumah ramah lingkungan atau Green Home merupakan rumah yang memerlukan biaya perawatan tinggi atau rumah yang hanya memiliki banyak lahan hijau.

krisis energi telah menjadi isu yang semakin penting seiring dengan kemajuan zaman. Memasuki abad ke-20, kebutuhan akan energi semakin besar dalam berbagai bidang. Hampir tidak satupun bidang yang tidak membutuhkan energi dalam menjalankan suatu kegiatan. Penerapan Green Home yang mengatur meminimalisir penggunaan energi untuk mengurangi pemborosan dalam penggunaan energi listrik terhadap perumahan. Salah satu acuan dalam penilaian konsep Green Building di Indonesia yaitu Greenship Homes Version 1.0 yang dipakai sebagai standar pada penelitian ini. 


\section{TINJAUAN KEPUSTAKAAN}

\subsection{Perumahan}

Perumahan merupakan tempat tinggal atau lingkungan hunian yang dilengkapi dengan sarana dan prasarana lingkungan. (UU RI No. 4 Tahun 1992). Menurut Anonim[1] rumah dikatakan sehat apabila: (1) Memenuhi kebutuhan fisik dasar seperti temperature lebih rendah dari udara di luar rumah, penerangan yang memadai, ventilasi yang nyaman, dan kebisingan 45-55 dB.A.; (2) Memenuhi kebutuhan kejiwaan; (3) Melindungi penghuninya dari penularan penyakit yang menular yaitu memiliki penyediaan air bersih, sarana pembuangan sampah dan saluran pembuangan air limbah yang saniter dan memenuhi syarat kesehatan; serta (4) Melindungi penghuninya dari kemungkinan terjadinya kecelakaan dan bahaya kebakaran, seperti fondasi rumah yang kokoh, tangga yang tidak curam, bahaya kebakaran karena arus pendek listrik, keracunan, bahkan dari ancaman kecelakaan lalu lintas, Sanropie[2].

\subsection{Persepsi}

Menurut Lestari[3] Persepsi adalah segala proses pemilihan, pengorganisasian dan penginterprestasian masukan informasi, sensasi yang diterima melalui penglihatan, perasaan, pendengaran, dan sentuhan untuk menghasilkan makna.

Persepsi dipengaruhi oleh 2 faktor, yaitu fakor internal dan faktor eksternal. Faktor internal merupakan faktor yang terdapat dalam diri individu yang mencakup fisiologis, perhatian, minat, kebutuhan, pengalaman dan suasana hati. Sedangkan faktor eksternal yang mempengaruhi persepsi merupakan karakteristik dari lingkungan dan obyek-obyek yang terlihat didalamnya. Elemen-elemen tersebut dapat mengubah sudut pandang seseorang terhadap dunia sekitarnya dan mempengaruhi bagaimana seseorang merasakannya atau menerimanya. Sementara itu faktor-faktor eksternal yang mempengaruhi persepsi adalah ukuran dan penempatan dari obyek, warna dan keunikan, Gibson[4].

\subsection{Konsep Green Building}

Green Building merupakan perencanaan dan perancangan bangunan melalui sebuah proses yang memperhatikan lingkungan dan menggunakan sumber daya secara efisien pada seluruh siklus hidup bangunan dari mulai pengolahan tapak, perancangan, pembangunan, penghunian, pemeliharaan, renovasi dan perubahan bangunan, Anonim[5].
Di Indonesia sendiri, ada sebuah lembaga bernama Green Building Council Indonesia (GBCI) yang hanya fokus untuk mendorong terciptanya gedunggedung ramah lingkungan. GBCI merupakan sebuah lembaga nirlaba yang berkomitmen penuh terhadap pendidikan masyarakat dalam mengaplikasikan praktikpraktik terbaik lingkungan dan memfasilitasi transformasi industri bangunan global yang berkelanjutan. GBCI merupakan Emerging Member dari World Green Building Council (WGBC) yang berpusat di Toronto, Kanada. WGBC saat ini beranggotakan 97 negara dan hanya memiliki satu GBC di setiap negara. GBCI sendiri didirikan pada tahun 2009 dan salah satu programnya adalah menyelenggarakan kegiatan Sertifikasi Bangunan Hijau di Indonesia berdasarkan perangkat penilaian khas Indonesia yang disebut Greenship.

Salah satu perangkat penilaian Green Homes untuk perumahan yaitu, Greenship Home Version 1.0. Berikut adalah kategori Green Homes menurut Greenship Home Version 1.0:

a. Tepat Guna Lahan (Appropriate Site Development).

b. Konservasi dan Efisiensi Energi (Energy Efficiency and Conservation).

c. Konservasi Air (Water Conservation).

d. Sumber dan Siklus Material (Material Resources and Cycle).

e. Kualitas Kenyamanan Udara (Indoor Air Health and Comfort).

f. Manajemen Lingkungan Bangunan (Building and Enviroment Management).

\section{$2.4 \quad$ Aspek Efisiensi Dan Konservasi Energi}

Di dalam penerapan Green Building terdapat tolak ukur yang harus dipenuhi sebagai persyaratan untuk tersertifikasinya bangunan sebagai Green Building salah satu kategori yang harus dipenuhi adalah Energy Eficiency and Conservation, untuk mencapai kategori tersebut terdapat 2 kriteria prasyarat, 5 kriteria kredit dan 1 kriteria bonus yang harus dipenuhi agar bangunan dikategorikan sebagai Green Building.

Pada aspek ini terdapat dua jenis kategori rating, yaitu rating prasyarat dan rating biasa. Rating prasyarat (P) adalah butir yang mutlak yang harus dipenuhi dan dalam suatu kategori. Apabila butir ini tidak dipenuhi, maka butir-butir rating lainnya dalam kategori ini tidak dinilai dan sehingga proses sertifikasi tidak bisa dilanjutkan. Berikutnya adalah rating biasa yang merupakan turunan dalam kategori selain butir prasyarat. Butir ini baru dinilai dan semua butir prasyarat dalam kategori tersebut telah terpenuhi atau dilaksanakan. 


\subsection{Skala Likert}

Menurut Riduwan [6] menjelaskan Skala Likert adalah skala yang digunakan untuk mengukur sikap, pendapat dan persepsi seseorang atau sekelompok tentang kejadian atau gejala sosial. Untuk mendapatkan jawaban harus dibuat instrumen (kuesioner) yang dihubungkan dengan bentuk pernyataan atau dukungan sikap yang diungkapkan dengan suatu kata-kata atau indikator tertentu.

Dalam penelitian ini, peneliti menggunakan jenis instrumen angket atau kuesioner dengan pemberian skor sebagai berikut:

Tabel 1. Skor pada Skala Likert

\begin{tabular}{lll}
\hline No. & Keterangan & Skor \\
\hline 1 & Sangat Penting & 5 \\
2 & Penting & 4 \\
3 & Ragu-Ragu & 3 \\
4 & Tidak Penting & 2 \\
5 & Sangat Tidak Penting & 1 \\
\hline
\end{tabular}

\subsection{Uji Validitas}

Uji validitas dilakukan bertujuan untuk menguji sejauh mana item kuesioner yang valid dan yang tidak valid. Hal ini dilakukan dengan mencari korelasi setiap item pertanyaan dengan skor total pertanyaan untuk hasil jawaban responden yang mempunyai skala pengukuran Interval, perhitungan korelasi antara pertanyaan kesatu dengan skor total digunakan alat uji korelasi Pearson (product moment coefisientof corelation) dengan rumus sebagai berikut:

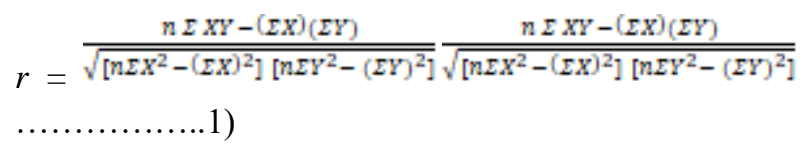

\section{Dimana :}

$$
\begin{array}{ll}
\mathrm{r} & : \text { Koefisien korelasi } \\
\sum \mathrm{X} & : \text { jumlah skor item pertanyan } \\
\sum \mathrm{Y} & : \text { jumlah skor total suatu variable } \\
\mathrm{n} & : \text { jumlah responden }
\end{array}
$$

\subsection{Uji Reliabilitas}

Menurut Morissan[7] uji reliabilitas merupakan indikator tingkat keandalan atau kepercayaan. Suatu pengukuran disebut reliable atau memiliki keandalan jika konsisten memberikan jawaban yang sama. Dalam hal penelitian, jika suatu pengukuran konsisten dari satu waktu ke waktu lainnya, maka pengukuran itu dapat diandalkan dan dapat dipercaya dalam derajat tertentu. Uji reliabilitas dilakukan dengan menggunakan metode Cronbach Alpha diukur berdasarkan skala Cronbach Alpha 0 sampai 1.

$r=\frac{k}{k-1}\left[1-\frac{\sum \sigma_{\frac{2}{b}}^{\frac{2}{2}}}{\sigma_{1}^{\frac{2}{1}}} r=\frac{k}{k-1}\left[1-\frac{\sum \sigma_{\frac{2}{4}}^{\frac{2}{2}}}{\sigma_{1}^{\frac{2}{2}}}\right.\right.$

Dimana :

r : reliabilitas instrument

$\mathrm{k} \quad$ : banyaknya butir pertanyaan atau banyaknya soal

$\sum \sigma 2 / \mathrm{b}$ : jumlah varian butir

$\sigma 2 / 1 \quad$ : varian total

Rumus untuk varian butir dan varian total :

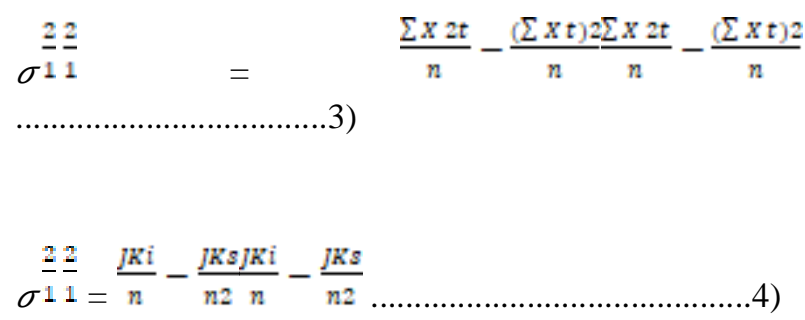

Dimana :

$$
\begin{array}{ll}
J k i & : \text { jumlah kuadrat seluruh butir } \\
J k s & : \text { jumlah kuadrat subjek } \\
\mathrm{n} & : \text { jumlah responden }
\end{array}
$$

\subsection{Methode of Successive Interval (MSI)}

Analisis statistik parametrik (statistik yang bergantung pada distribusi tertentu dan yang menetapkan adanya syarat-syarat tertentu tentang parameter populasi seperti pengujian hipotesis dan penaksiran parameter) memerlukan terpenuhinya persyaratan bahwa skala pengukuran minimal interval, sedangkan data penelitian diperoleh data yang memberikan skala pengukuran ordinal, sehingga agar analisis tersebut dapat dilanjutkan maka skala pengukuran ordinal harus dinaikkan (ditransformasikan) kedalam skala interval dengan menggunakan Methode Successive Interval (MSI). 
Menurut Sedarmayanti[8] Methode of Successive Interval adalah sebuah metode penskalaan untuk menaikan skala pengukuran ordinal ke skala pengukuran interval.

\subsection{Analisis Deskriptif}

Menurut Sugiono[9] analisis deskriptif adalah analisis yang berfungsi untuk mendeskripsikan atau memberi gambaran terhadap objek yang diteliti melalui data sampel atau populasi sebagaimana adanya. Data dari angket dalam penelitian ini merupakan data kuantitatif yang akan dianalisa secara deskriptif persentase.

Nilai rata-rata (mean)

$\bar{x}=\frac{x i}{n} \bar{x}=\frac{x i}{n}$

Keterangan :

$$
\begin{array}{ll}
\bar{x} \bar{x} & =\text { nilai rata-rata } \\
x i & =\text { data yang diambil } \\
n & =\text { jumlah data }
\end{array}
$$

Untuk selanjutnya perhitungan persentase skor dari setiap indikator digunakan rumus sebagai berikut:

Skor $=\frac{\text { total skor }(A)}{\text { nilai total }(B)} \times 100 \%$
Skor $=\frac{\text { total skor }(A)}{\text { nilai total }(B)} \times 100 \%$

Dimana :

- $\quad$ Total skor $(A)=$ Total nilai skor $(1-5)$

- Nilai total $(B)=$ Total nilai skor maksimum tiap klausul

Interpretasi dari hasil rumus diatas diterjemahkan menurut Tabel 4 sebagai berikut

Tabel 2. Kriteria Skor Mean

\begin{tabular}{lll}
\hline No. & Persentase Skor & Kualifikasi \\
\hline 1 & Angka $81 \%-100 \%$ & Sangat Baik \\
2 & Angka $61 \%-80 \%$ & Cukup Baik \\
3 & Angka $41 \%-60 \%$ & Baik \\
4 & Angka $21 \%-40 \%$ & Kurang Baik \\
5 & Angka 0\%-20\% & Sangat Tidak Baik \\
\hline
\end{tabular}

\section{METODE PENELITIAN \\ 3.1 Lokasi dan Objek Penelitian}

Penelitian ini dilakukan di Komplek Perumahan Villa Citra Di Gampong Pineung, Syiah kuala, Kota Banda Aceh, terdapat 60 rumah di Dusun tersebut. Dari total semua rumah yang dihuni, 46 merupakan rumah pribadi sedangkan 14 sisanya adalah rumah sewa.

\subsection{Metode Pengumpulan Data}

Data dalam penelitian ini menggunakan data primer dan data sekunder. Pengumpulan data primer dilakukan dengan menentukan target responden, merancang kuesioner, mendistribusikan kuesioner dan melakukan wawancara dengan responden. Sedangkan untuk data sekunder berupa studi literatur, kajian kepustakaan, jurnal ilmiah, buku-buku referensi, dan laporan penelitian terdahulu yang relevan.

\subsection{Instrumen Penelitian}

Instrumen penelitian menggunakan alat bantu pengumpulan data. Pada penelitian ini instrumen penelitian berupa kuesioner yang mana variabelnya diidentifikasi dari penelitian sebelumnya dan berdasarkan acuan Greenship Homes Version 1.0.

\subsection{Rancangan Kuesioner}

Rancangan kuisioner pada penelitian ini dibagi 3 bagian, yaitu :

1. Karakteristik Responden dan Informasi Umum Pada bagian ini responden menguraikan atau memberikan penjelasan mengenai identitas diri responden dan beberapa pertanyaan yang menjelaskan aktifitas dan kebiasaan responden terhadap penggunaan dan penghematan energi listrik di lingkungan perumahan tersebut.

2. Persepsi Responden Terhadap penghematan energi listrik

Kuisioner ini berisi beberapa pernyataan mengenai penghematan energi listrik yang akan dijawab langsung oleh responden. Terdapat 7 variabel pernyataan pada Kuisioner B yang akan dijawab oleh responden dengan cara checklist pada salah satu nilai sesuai dengan persepsinya. Variabel yang menjadi indikator pada kuisioner ini dapat dilihat pada Tabel

\begin{tabular}{|c|c|}
\hline No. & Uraian Pernyataan \\
\hline 1 & $\begin{array}{l}\text { Seberapa sering anda memperhatikan waktu } \\
\text { beban puncak dalam penggunaan listrik di } \\
\text { rumah? }\end{array}$ \\
\hline 2 & $\begin{array}{l}\text { Menurut anda, pentingkah memilih peralatan } \\
\text { elektronik yang rendah watt? }\end{array}$ \\
\hline 3 & $\begin{array}{l}\text { Seberapa sering anda mematikan lampu } \\
\text { kamar saat meninggalkan ruangan dalam } \\
\text { waktu yang cukup lama? }\end{array}$ \\
\hline
\end{tabular}
3 berikut ini:

Tabel 3. Variabel Penelitian 
Seberapa sering anda mencabut semua

4 bagian elektronik yang tidak terpakai dari sumber listrik?

Setujukah anda dalam upaya untuk meningkatkan kesadaran masyararakat dan memotivasi masyarakat untuk ikut melaksanakan penghematan energi listrik?

Seberapa sering anda membatasi penggunaan pompa air saat digunakan?

Menanggap sebuah penghematan energi listrik, setujukah anda mengurangi pemakaian listrik pada jam puncak pukul 17.00 - 22.00 WIB?

3. Penerapan Efisiensi dan Konservasi Energi sesuai Greenship Homes Version 1.0.

Kuisioner ini berisi tolok ukur kriteria Efisiensi dan Konservasi Energi sesuai acuan Greenship Homes Version 1.0 yang akan di checklist oleh peneliti saat melakukan wawancara langsung dengan responden.

Tabel 4. Kriteria Efisiensi dan Konservasi Energi sesuai Greenship Homes Version 1.0.

\begin{tabular}{cl}
\hline Kode & \multicolumn{1}{c}{ Kriteria } \\
\hline EEC P1 & Meteran Listrik (Electricity Metering) \\
EEC P2 & $\begin{array}{l}\text { Analisis Desain Pasif (Passive Design } \\
\text { Analysis) }\end{array}$ \\
EEC 1 & Sub Meteran (Sub-Metering) \\
EEC 2 & Pencahayaan Buatan (Artificial Lighting) \\
& Pengkondisian Udara (Thermal \\
EEC 3 & Condition) \\
EEC 4 & Reduksi Panas (Heat Reduction) \\
& Piranti Rumah Tangga Hemat Energi \\
EEC 5 & $\begin{array}{l}\text { Energy Saving Home Appliances) } \\
\text { Sumber Energi Terbarukan (Renewable } \\
\text { Energy Sources) }\end{array}$ \\
\hline
\end{tabular}

\subsection{Metode Pengolahan Data}

Pada penelitian ini, dilakukan beberapa analisis data statistik yaitu, penentuan jumlah sampel, uji validitas, reabilitas, Methode of Successive Interval (MSI) dan analisis deskriptif.

3.6 Uji Validitas
Uji validitas pada penelitian ini dilakukan untuk menguji data persepsi responden terhadap penghematan energi listrik dengan menggunakan persamaan (1). Untuk responden sebanyak 60 orang dan didapatkan $r$ tabel senilai 0,250. Jika $r$ hitung $\geq 0,250$ maka butir instrumen dinyatakan valid. Namun apabila $r$ hitung $\leq$ 0,250 maka butir dalam instrumen tersebut dinyatakan tidak valid.

\subsection{Uji Reliabilitas}

Uji reliabilitas merupakan suatu instrument yang cukup dapat dipercaya untuk digunakan sebagai alat pengumpul data. Rumus yang digunakan pada pengujian reliablitas adalah rumus yang terdapat pada persamaan (2), (3) dan (4). Adapun pengujian dengan koefisien cornbach alpha hasil yang dianggap valid harus lebih besar atau sama dengan 0,6 .

\subsection{Analisis Deskriptif}

Pengolahan data dilakukan dengan analisis deskriptif. Analisis deskriptif dihitung rata-rata (mean) dan rata-rata peringkat (mean rangking) dari setiap variabel penelitian. Adapun hasil disajikan dalam bentuk tabel.

\section{HASIL DAN PEMBAHASAN}

\subsection{Hasil Uji Validitas}

Hasil perhitungan nilai uji validitas yang dihitung menggunakan SPSS untuk kuesioner persepsi terhadap penghematan energi listrik dapat dilihat pada Tabel 5 berikut ini:

Tabel 5. Hasil Uji Validitas

\begin{tabular}{ccc}
\hline No. & r hasil & Keterangan \\
\hline A1 & 0,617 & Valid \\
A2 & 0,443 & Valid \\
A3 & 0,324 & Valid \\
A4 & 0,545 & Valid \\
A5 & 0,445 & Valid \\
A6 & 0,515 & Valid \\
A7 & 0,448 & Valid
\end{tabular}

\subsection{Hasil Uji Reliabilitas}

Hasil perhitungan nilai uji reliabilitas yang dihitung menggunakan SPSS untuk kuesioner terhadap 
penghematan energi listrik dapat dilihat pada Tabel 6 dibawah ini:

Tabel 6. Hasil uji reliabilitas

\begin{tabular}{clcc}
\hline No. & Variabel & $\begin{array}{c}\text { Cronbach's } \\
\text { Alpha }\end{array}$ & $\begin{array}{c}\text { Jumlah } \\
\text { Variabel }\end{array}$ \\
\hline 1 & $\begin{array}{l}\text { Persepsi responden } \\
\text { terhadap penghematan } \\
\text { energi listrik }\end{array}$ & 0.744 & 7 \\
\hline
\end{tabular}

\subsection{Methode of Successive Interval (MSI)}

Setelah melakukan pengujian data, maka perlu dilakukan perubahan skala data dari data ordinal menjadi data interval agar dapat dirata-ratakan dan dianalisis secara deskriptif. Langkah ini dilakukan menggunakan bantuan aplikasi Microsoft excel dan statcal.

\subsection{Analisa Deskriptif}

Berdasarkan pernyataan pada Kuisioner B, 6 variabel disimpulkan cukup penting atau cukup setuju dan cukup sering untuk diterapkan sedangkan 1 variabel lainnya disimpulkan tidak sering untuk diterapkan. Untuk persepsi responden terhadap penghematan energi listrik dengan nilai tertinggi terdapat pada variabel A7 yaitu, mengurangi pemakaian listrik pada jam puncak pukul 17.00 - 22.00 dengan nilai mean 3,48. Sedangkan untuk persepsi dengan nilai terendah terdapat pada variabel A6 yaitu, membatasi penggunaan pompa air saat digunakan dengan nilai mean 2,02 dan masuk dalam kategori tidak sering. Secara keseluruhan, nilai mean persepsi responden terhadap penghematan energi listrik yaitu 3,17, sedangkan persentasenya yaitu $63,61 \%$. Secara keseluruhan, analisis deskriptif Kuisioner B dapat dilihat pada Tabel 6 berikut ini:

Tabel 7. Analisis Deskriptif Persepsi Responden Terhadap penghematan energi listrik

\begin{tabular}{cccl}
\hline No. & Mean & Persentase & Keterangan \\
\hline A1 & 3,06 & $61,26 \%$ & Cukup Sering \\
A2 & 3,48 & $69,75 \%$ & Cukup Penting \\
A3 & 3,48 & $69,75 \%$ & Cukup Sering \\
A4 & 3,22 & $64,56 \%$ & Cukup Sering \\
A5 & 3,48 & $69,74 \%$ & Cukup Setuju \\
A6 & 2,02 & $40,49 \%$ & Tidak Sering \\
A7 & 3,48 & $69,77 \%$ & Cukup Setuju
\end{tabular}

Kriteria dari penerapan aspek efisiensi dan konservasi energi sesuai acuan Greenship Homes Version 1.0 terdapat 10 tolok ukur yang dinilai. Beberapa kriteria yang sudah diterapkan secara sempurna yaitu, adanya upaya desain atau penggunaan bahan bangunan yang dapat mereduksi panas pada seluruh atap dan menggunakan peralatan elektrik pada rumah yang berlabel hemat energi minimum sebanyak $75 \%$ dari total daya (Watt) peralatan elektrik. Sedangkan kriteria dengan nilai penerapan terendah terdapat pada kriteria penggunaan fitur otomatisasi seperti sensor gerak, timer, atau sensor cahaya minimal pada 1 area atau ruangan rumah yaitu sebesar 22\%. Secara keseluruhan, nilai persentase penerapan aspek efisiensi dan konservasi energi yaitu, 55\% dan dilihat pada Tabel 8 berikut ini:

Tabel 8. Analisis Deskriptif Penerapan Aspek Efisiensi dan Konservasi Energi

\begin{tabular}{llll}
\hline No. & Kriteria & Presentase & Kategori \\
\hline 1 & EEC 1 & $39 \%$ & Kurang Baik \\
2 & EEC 2 & $30 \%$ & Kurang Baik \\
3 & EEC 3 & $50 \%$ & Baik \\
4 & EEC 4 & $59 \%$ & Baik \\
5 & EEC 5 & $95 \%$ & Sangat Baik \\
\hline & Rata-rata & $55 \%$ & Baik \\
\hline
\end{tabular}

\subsection{Pembahasan}

Berdasarkan hasil dari penelitian, secara keseluruhan tingkat penerapan Aspek Efisiensi dan Konservasi Energi pada perumahan di Komplek Villa Citra adalah sebesar $55 \%$ atau tingkat penerapan dapat dikategorikan baik. Hal ini menunjukkan bahwa adanya kepedulian responden terhadap lingkungannya guna mereduksi dampak negatif terhadap lingkungan seperti isu pemanasan global. Apabila dikaitkan dengan penelitian sebelumnya yang juga melakukan penelitian tentang penerapan Green Building pada perumahan di Kota Banda Aceh, terdapat 77 kriteria yang dinilai pada 3 lokasi perumahan yang berbeda dan ketiganya menunjukkan hasil penerapan sebesar $63 \%$ pada Komplek Perumahan Blower Setia Indah, 61\% pada Komplek Perumahan Jeumpet Residence dan 59\% pada Komplek Perumahan Firdaus Lamnyong.

\section{Kesimpulan Dan Saran}

\section{$5.1 \quad$ Kesimpulan}


1. $1 . \quad$ Persepsi responden di Dusun Tgk. Chik dipineung terhadap Penghematan Energi Listrik yaitu, sebesar $63,61 \%$ dengan nilai persepsi terendah pada variabel penggunaan pompa air sebesar 40,49\%, dan nilai persepsi tertinggi terdapat pada variabel penanggapan sebuah penghematan energi listrik dan mengurangi pemakaian listrik pada jam puncak pukul $17.00-22.00$ yaitu, sebesar $69,77 \%$.

2. Dari 5 kriteria penilaian pada aspek Efisiensi dan Konservasi Energi yang ada dalam acuan Greenship Homes Version 1.0, rumah tinggal di Dusun Tgk. Chik dipineung memperoleh rata-rata total poin sebesar 17 poin dari 18 poin maksimal dengan persentase sebesar $55 \%$ atau dapat dikategorikan ke dalam kategori baik, dengan nilai penerapan terendah terdapat pada kriteria Pencahayaan Buatan yaitu, sebesar 30\%, sedangkan penerapan tertinggi terdapat pada kriteria Piranti Rumah Hemat Energi yaitu, sebesar $95 \%$.

\subsection{Saran}

Diharapakan pada penelitian berikutnya dapat menganalisis penerapan efisiensi dan konservasi energi berdasarkan greenship untuk rumah tinggal yang berada pada komplek perumahan yang sedang berkembang.

\section{Daftar Kepustakaan}

[1] Anonim, (1992). Undang-Undang Republik Indonesia Nomor 4 Tahun 1992 Tentang Perubahan Dan Pemukiman.

[2] Sanropie D., 1992. Pedoman Bidang Studi Perencanaan Penyehatan Lingkungan Pemukiman. Departemen Kesehatan R.I. Jakarta.

[3] Lestari, I. 2013. Pengembangan Bahan Ajar Berbasis Kompetensi. Padang: Akademia.

[4] Gibson, J. L., dkk. 2014. Organisasi: Perilaku, Struktur, Proses. Diterjemahkan oleh Ninuk Adriani. Jakarta: Binarupa Aksara.

[5] Anonim, (2011). Green Building Council Indonesia. Panduan Bangunan Hijau GREENSHIP Versi 1.0.

[6] Riduwan, 2003, Metode dan Teknik Menyusun Tesis, , Alfabeta, Bandung.

[7] Morissan, (2012). Metode Penelitian Survey. Jakarta: Kencana Prenada Media Group.

[8] Sedarmayanti, 2011. Metodologi Penelitian. PT Refika Aditama, Bandung.

[9] Sugiyono, (2010). Metode Penelitian Kuantitatif Kualitatif dan R\&D, Alfabeta, Bandung. 